\title{
METODOLOGIAS ATIVAS DE APRENDIZAGEM: CONTRIBUIÇÕES PARA A INOVAÇÃO PEDAGÓGICA NA DOCÊNCIA UNIVERSITÁRIA
}

\author{
Daniella Oliveira da silva $^{1}$; Amali de Angelis Mussi ${ }^{2}$ \\ 1. Bolsista PROBIC/UEFS, Graduanda em Pedagogia, Universidade Estadual de Feira de Santana, e-mail: \\ daniellaosp@gmail.com \\ 2. Orientadora, Departamento de Educação, Universidade Estadual de Feira de Santana, e-mail: amalimussi@ hotmail.com
}

PALAVRAS-CHAVE: Docência no Ensino Superior. Aprendizagem. Metodologias Ativas de Aprendizagem.

\section{INTRODUÇÃO}

Nesse texto, apresentamos um recorte dos dados obtidos através da pesquisa "Metodologias ativas de aprendizagem: contribuições para a inovação pedagógica na docência universitária", que tem como objetivo a investigação de diferentes propostas de metodologias ativas para a aprendizagem no ensino superior. Esse estudo é fruto de uma pesquisa maior desenvolvida pelo Núcleo de Estudo e Pesquisa sobre Pedagogia Universitária (NEPPU) intitulada "Inovação da prática pedagógica de professores do ensino universitário pela pesquisa-ação colaborativa”, em uma Universidade Pública do interior da Bahia.

Para a produção desse estudo, partimos da premissa de que o grande desafio deste início de século no âmbito acadêmico é a crescente busca por metodologias inovadoras que possibilitem uma prática de ensino consubstanciada e capaz de superar as práticas puramente tradicionais de ensino, para alcançar efetivamente a formação integral do sujeito. Cabe destacar que a concepção de aprendizagem defendida na atualidade é aquela decorrente de uma visão que busca desenvolver o protagonismo do estudante na gestão de seu próprio processo de aprendizagem, ultrapassando a mera transmissão de conhecimentos do docente para o estudante. Instigada por esse contexto, buscamos identificar, junto a professores de ensino superior, participantes da investigação, as experiências metodológicas que possibilitaram a aprendizagem significativa dos estudantes na visão dos docentes. Neste estudo, traremos a contribuição de Fazenda (2008); Almeida (2015); Santana (2006); Favarão (2004) e outros.

\section{METODOLOGIA}

Para a coleta de dados, foi aplicado um questionário com sete questões, sendo três abertas (sobre as experiências metodológicas) e quatro fechadas (sobre o conhecimento das metodologias ativas), a sete professores universitários que se dispuseram a participar da pesquisa maior (pesquisa-ação colaborativa), a qual este estudo está articulado, em uma universidade pública baiana. O estudo realizado é de cunho qualitativo e nele apresentamos os dados obtidos através das questões fechadas do questionário, que diz respeito às experiências metodológicas vivenciadas pelos docentes universitários. Os dados produzidos passaram pelo processo de análise de conteúdo do tipo temática (BARDIN, 2001), que se constitui em uma técnica, cuja análise interpretativa do conhecimento é construída a partir da realidade histórico-social dos indivíduos. Nos resultados, selecionamos amostras de extratos para representar o grupo de professores investigados. 


\section{ANÁLISE E DISCUSSÃO DOS RESULTADOS}

Nessa seção, apresentamos os dados que revelam experiências metodológicas que possibilitaram a aprendizagem significativa dos estudantes sob o ponto de vista dos docentes. A maioria das situações de ensino explicitadas por eles apresentam princípios das Metodologias Ativas de aprendizagem, tais como problematização do ensino, valorização dos conhecimentos prévios, e busca pelo desenvolvimento da autonomia do estudante. A seguir, apresentamos as principais categorias que emergiram sobre as experiências relatadas.

\section{- Articulação entre teoria e prática}

Convidados a relatarem sobre experiências de ensino realizadas no ensino superior, especialmente aquelas no qual os docentes perceberam que seus estudantes realmente aprenderam, a docente P1 enfatizou que os estudantes aprendem os conteúdos lecionados em sua disciplina quando fazem articulação entre teoria e prática nas aulas de visita técnica: Em visita técnica, normalmente posso observar que vários estudantes conseguem fazer as correlações dos assuntos estudados em minhas aulas com as situações vistas no local. Este depoimento revela uma cisão, historicamente construída, entre teoria e prática.

Moreira (2014) adverte que essa cisão deve ser discutida seriamente, uma vez que a relação entre a teoria e a prática apresenta-se fragilizada no meio acadêmico, pois tanto docentes quanto estudantes destacam a dicotomia existente na aprendizagem de conteúdos, entre teoria e prática. Entretanto, Moreira (2014), afirma que grande parte dos docentes busca estabelecer relações entre a teoria lecionada em suas disciplinas com a realidade do mundo do trabalho, o que demonstra uma tentativa de superação dessa cisão. Os relatos dos professores participantes também destacam que a teoria serve de apoio para o acadêmico definir estratégias de ação. Teoria e prática estão, assim, vinculadas pelo próprio processo de geração de conhecimento, numa perspectiva metodológica considerada inovadora, aos nossos participantes.

\section{- Exercícios lúdicos}

Outra metodologia que aparece nos relatos dos docentes, ainda que de forma tímida, se refere ao uso da ludicidade como metodologia de aprendizagem. As docentes P3 e P4 expuseram que as experiências lúdicas tem ganhado um espaço significativo em suas práticas de ensino. A docente P3 relata que: "[...] uma experiência metodológica que acho bem válida é aplicar exercícios na forma lúdica, utilizo muito a palavra-cruzada e vejo bastante interesse por parte dos alunos". A docente $\mathrm{P} 4$, afirma que faz uso do lúdico como um instrumento facilitador para a aprendizagem de seus estudantes: Gosto de fazer representações [...]. Brinco com a Química porque acho que estudar Química é uma diversão. A docente ainda relatou que para introduzir alguns conteúdos de sua disciplina faz uso da contação de histórias, que é outro instrumento lúdico.

Considerando que o ensino de química, em geral, é tradicional, centrado na simples memorização e repetição de nomes, fórmulas e cálculos, totalmente desvinculados do dia-adia e da realidade em que os estudantes se encontram, como assinalado pelo depoimento da docente P4. Percebemos então, que ambas professoras (P4 e P3) estão buscando superar esse ensino maçante e monótono como o uso de recursos lúdicos.Estudos realizados por Mariscal \& Iglesias (2009) e Santana (2006) revelam que o lúdico tem sido uma metodologias bastante aplicado no ensino de química como uma estratégia de ensino para a aquisição de conceitos químicos, por exemplo, os jogos lúdicos. Dessa maneira, podemos afirmar que as docentes estão adotando essa nova perspectiva do ensino da química em suas práticas, lançando mão de estratégias com exercícios lúdicos, representação e contação de histórias.

\section{- Práticas de Avaliação}

A prática de avaliação ganha relevo para os professores participantes enqunato um instrumento que pode exigir dos estudantes, processos complexos de aprendizagens, que 
passam por capacidade de análise fundamentada, interpretação relacionada, sínteses elaboradas. Nesse sentido, a docente P3 julga ser eficiente em sua prática de ensino a correção das provas no dia posterior a sua realização junto com os estudantes, de modo que estes possam repensar e aprender com seus próprios erros: [...] julgo ser eficiente a correção das provas no dia posterior as avaliações, [...] faço as discussões de todas as questões, para cada questão eu reúno em um papel todas as repostas equivocadas que os alunos descreveram nas provas, assim todos aprendem com os erros dos demais (P3).

A questão das práticas de avaliação merece um destaque, ainda que sucinto: esse momento também pode fazer parte de momentos de aprendizagens pelos estudantes, quando a sua proposta é problematizadora, na perspectiva da elaboração fundamentada de conceitos, ou mesmo da aplicação de teorias em situações contextualizadas, e indo além, na perspectiva da avaliação formadora. As práticas avaliativas, quando inseridas no contexto da aprendizagem, devidamente planejadas e portadoras de sentido aos estudantes, podem contribuir incisivamente ao processo de desenvolvimento da autonomia do estudante diante de seu próprio processo de aprendizagem.

\section{- Interdisciplinaridade}

A interdisciplinaridade, compreendida como um movimento que vai além da busca das conexões de conteúdos entre as disciplinas visando à interação professor-aluno, aluno-aluno, para dotar de significados os conteúdos da realidade (relação teoria/prática), requer uma nova atitude do professor e do estudante diante da questão do conhecimento, colocando-os em questão (FAZENDA, 2008). Essa perspectiva da interdisciplinaridade aparece nos dados apreendidos nessa investigação como uma oportunidade metodológica de garantir a aprendizagem dos estudantes universitários.

A docente P6 relatou que uma das experiências metodológicas que sentiu que seus estudantes realmente aprenderam foi quando realizou uma aula na qual convidou três professores de diferentes áreas (Matemática, Geografia e Física) para discutirem o tema "Idade Média" com os estudantes do curso de Letras: A aula foi ministrada por três professores de áreas distintas. Os alunos tiveram a oportunidade de adquirir um conhecimento mais generalizado. As discussões foram intensas. [...] Os alunos ficaram interessados, estimulados, elogiaram muito o encontro e foi possível perceber que a aprendizagem realmente ocorreu. O relato da docente nos remete a um eixo articulador tão pregado na universidade, a interdisciplinaridade. Tal proposta é indispensável para se aplicar no processo de educação na sociedade atual, pois a partir dela o estudante pode desenvolver a visão da totalidade, a criticidade e a criatividade, além de perceber a multiplicidade de relações entre as disciplinas (FAVARÃO et al, 2004).

\section{- Simulações com os estudantes - Avaliação formativa}

As simulações com os estudantes são consideradas práticas metodológicas inovadoras pelos professores participantes da pesquisa, a partir da compreensão de que se tratam de situações que exigem habilidades de convívio, respeito ao grupo, postura proativa sobre o objeto de conhecimento. Os depoimentos das docentes P3 e P7 revelam uma valorização do estudante na produção da avaliação da aprendizagem e na produção do conhecimento, o que nos faz inferir que as docentes estão concebendo a avaliação da aprendizagem como um processo que deve ser elaborado coletivamente, tanto pelo docente quanto pelo estudante. Vejamos: P7: [...] eu quis trabalhar a questão da avaliação da aprendizagem em diferentes modalidades. Simulei situações com os alunos e juntos formos criando estratégias e metodologias para produzir a avaliação que melhor se adequasse aos estudantes. [...] Assim as elaborações de provas e avaliações deixaram de ter o foco nos estágios no conteúdo e passaram a considerar o aprendiz em suas necessidades reais. Instaurei nesse contexto a avaliação formativa. 
A Técnica de Associação Livre de Palavras (TALP) foi utilizada pela docente P3 para avaliar o conhecimento dos estudantes sobre sua disciplina: P3: Já utilizei em sala de aula a TALP, para avaliar o que os alunos tinham noção sobre a disciplina, na aula seguinte mostrei em números os resultados e discutimos sobre os conceitos levantados pelos mesmos. Os alunos começam a relatar experiências próprias sobre o tema, muito interessante a troca de experiências. Esse dado aponta o uso da avaliação da aprendizagem dentro de uma perspectiva emergente, ou seja, para além da verificação da aprendizagem (ALMEIDA, 2011). Com isso, demonstra uma superação da visão positivista e racionalista na avaliação tradicional, que centra o processo de avaliação como uma simples retenção mecânica dos conteúdos, para uma visão que considere o estudante em suas necessidades reais de aprendizagem. Ao permitir que os estudantes participem e colaborem nesse processo, pode-se romper com uma visão conservadora que outorga ao professor a autoridade de ser o único avaliador (ALMEIDA, 2011).

\section{CONCLUSÃO}

O estudo realizado apontou que os docentes do ensino superior apresentam, mesmo que timidamente, iniciativas de mudanças em suas práticas. Os participantes da investigação indicam que realizam um esforço para que o processo de ensino aprendizagem se concretize efetivamente. Práticas essas, desenvolvidas a partir dos modelos que tiveram, dos acertos e erros que realizaram. Além disso, esses docentes demonstram que estão abertos a adotarem em suas práticas de ensino os princípios das Metodologias Ativas de aprendizagem, considerando o estudante como um sujeito ativo no processo de ensino e aprendizagem, ao mesmo tempo estes docentes apontam a falta de tempo como um dos principais empecilhos para uma mudança significativa em suas práticas de ensino.

Esta realidade reitera a importância de se continuar investindo em estudos sobre as Metodologias Ativas de aprendizagem e suas aplicações teóricas e práticas, uma vez que o conhecimento sobre elas significa um grande diferencial na ação do docente universitário. Outra importante consideração a ser destacada, se refere à necessidade de investimentos em políticas que garantam o desenvolvimento profissional de professores, a socialização de práticas, a (re)construção da docência, tendo em vista as complexidades que se apresentam no contexto do processo pedagógico no ensino superior brasileiro. Portanto, são provocações brevemente discutidas aqui, que merecem a nossa atenção!

\section{REFERÊNCIAS}

ALMEIDA, Elisa Carneiro Santos de. Aprendizagem na educação superior: a auto-transformação do estudante na aprendizagem baseada em problemas (problembasedlearning - pbl). Dissertação de Mestrado. UEFS, 2015.

BARDIN, Laurence. Análise de conteúdo. Lisboa: Edições 70, 2001.

FAVARÃO, N. R. L.; ARAÚJO. C. S. A. Importância da Interdisciplinaridadae no Ensino Superior. EDUCERE. Umuarama, v.4, n.2, p.103-115, jul./dez., 2004.

FAZENDA, Ivani Catarina A. (org.). O que é interdisciplinaridade? São Paulo: Cortez, 2008.

MARISCAL, A. J. F.; IGLESIAS, M. J. Soletrando o Brasil com símbolos químicos. Química nova na escola, vol. $31 \mathrm{n}^{\circ} 1,2009$. pág 31 - 33.

MOREIRA, Daniele de Jesus Gomes. Necessidades formativas no campo pedagógico: a perspectiva do desenvolvimento profissional de docentes iniciantes da UEFS. Dissertação de Mestrado. UEFS, 2014.

SANTANA, Eliana Moraes de - A Influência de atividades lúdicas na aprendizagem de conceitos químicos. Universidade de São Paulo, Instituto de Física - Programa de PósGraduação Interunidades em Ensino de Ciências - 2006. 